\title{
SOVIET IDENTITY IN DISCOURSE OF KAZAKHSTAN
}

\author{
GAZINUR GIZDATOV \\ Kazakh University of International Relations \& World Languages \\ gizdat@mail.ru
}

\section{ABSTRACT}

The present article is dedicated to an analysis of Soviet identity in the discourse of modern Kazakhstan. The language in the post-Soviet discourse, as it is shown in this paper, is no longer a phenomenon of culture and serves only as a means of capturing and transmitting information. By linguistic manifestations of the last true desire for common stereotypes, standard and tarnish language. In this article (based on publicity, domestic and artistic discourses) identified the main speech strategy in post-Soviet discourse. That include logic-chopping, Offices and simulative anthropocentric interpretation.

KEY WORDS: cognitive models; discourse; speech strategies; rhetorical features.

Traditionally, it is considered that the population of Kazakhstan (primarily Kazakhs) has been russified and "immersed" in Soviet ideology. Post-Soviet reality became a symbol of the current sense and the Kazakh authorities. Explanation of the above is also clear:

We cannot forget that how a particular resource that was directly lived through has part of the surround experience, only the Soviet experience is the spring board from which Kazakhstan is repelled in the selection of self-identification guide lines after independence (Molotov Cocktail 2014: 34).

Russian researchers also point out that the mass consciousness and behavior of Russians has only changed a little, and they are not that different from "homo soveticus":

The crystallization of the cultural and political forces in Russia is at the early stage. This is manifested as significant part of apolitical citizens, political and legal cognitive vacuum in the mass consciousness, and immaturity, instability of the most political parties, unions, associations (Zaslavsky 2004: 344).

However, Russia, last year, has shown something else. It is best described as a manipulation of public opinion and the result of it is the "tunnel thinking", acquired in the last year by Russians and distinguished as from the Soviet identity. The Post-Soviet discourse in Russia is expressed in the special ideology which is an example of symbiosis of the Soviet great-power heritage and modern Russian nationalism, ideally embodied in the concept "krymnash" (i.e. Crimea is ours).

Prospects for the development of languages in the former Soviet Union are designated by experts from different areas very precisely, including the traditional "barbarization" ("Americanization") of all languages, including Russian, Kazakh, etc. We will agree in this case with a reflection in language 
practice of the phenomenon of globalization in all former Soviet Union states and in Kazakhstan in particular. The above also explains that the main distinction (and respectively-uniting) in the Post-Soviet republic occurs not on national, religious, language, or other aspects, but according to social status.

Here and now we will focus on some of the phenomena observed in the language of Kazakhstan. These trends are quite natural, and, at first glance, adequate. Kazakh and Russian languages in business, scientific and cultural life of Kazakhstan have their place ranked. In the majority of the manifestations of Kazakh and, perhaps, Russian in political and business spheres are equal to the status declared by official rhetoric.

What is the defining cognitive strategy in the Kazakhstan Russianspeaking discourse?

Of course, the introduction of an idealized cognitive model paradigm in the study of speech activity is a definite means of summarizing. A person usually is not aware of structures that guided his linguistic thinking: cognitive structures are not consciously understood when thinking, but it is thought that they impose one form there than another. In the psychological paradigm, the concept of a "cognitive state of a native speaker", is important, as we cannot consider any model of knowledge representation. Certainly, the introduction of an idealized cognitive model to a paradigm of studying speech activity is a certain means of generalization the tasks involved.

The person usually doesn't realize the structures directing his language thinking: informative structures aren't realized content of thinking, however they impose to use one form, but not another. Let us note that the similar aspect of research is different according to the social theory of P. Bourdieu in which use of language is equated to use of concepts:

The environment associated with a certain class of living conditions makes habitus, that is system of the strong, acquired predispositions, the structured structures intended for functioning as the structured structures that is as the principles which generate and will organize practice and granting (Bourdieu 1995: 17-18).

To some extent, the concept of habitus in Bourdieu is objective; it is different from the other individual cognitive systems.

Cognitive Model sinth is interpretation can and should act as "strategic rules" hidden behind the perception of practice.

In today's Kazakhstan discourse, regarding all its specific manifestations (domestic, political, legal, journalistic and so on), the following cognitive model - anthropocentrism of interpretation is most accurate. "I - schemes" (in L. Hell and D. Zigler's terminology [Hell, Zigler 1997]) in many respects provide speed of decision-making, reminiscence and reconstruction, an assessment and denial which does not really fit the "I - schemes". We will give an example of how Russian language is reflected in associative thinking of Russians in Russia and Russian-speakers in Kazakhstan (RAD - the associations received in Russia on 
words-incentives [The Russian associative dictionary 1994]-, KAD - the associations recorded at poll on the same words in Kazakhstan [Gizdatov 1998]). Operation side notification and comparison of the structures of knowledge reflected in associative thinking allow you to see not only a set contained in the semantic memory of human knowledge about the world, but also the dynamic nature of cognitive abilities-strategies to deal with preknowledge structures. The most computability of the following -in the Kazakh version of Russian language, there are no "myths" or cultural stereotypes. Not to be unfounded, we are giving an example of how the Russian language is reflected in associative thinking Russian in Russia and Russian in Kazakhstan (Rus-Association received in Russia-word stimuli [Russian dictionary associative 1994]), Kaz-Association recorded in the survey for the same words in Kazakhstan (Gizdatov1998).

Word-association is arranged according to the frequency, the numbers of associative reactions in both cases are similar (these are the most frequent responses):

- Life-Rus: deaths 62, beautiful 30, long, good 16, short 13, "tin" (expression from a cartoon), hard 12, my live 9, long 8;

- Life-Kaz: death 20, happiness, 17, long 16, joy 13, a short 7.

- Good-Rus: people 72, uncle 52, evil 46,day 29, a friend, little 26, good 13, evening 12, Dad 9, well done 8;

- Good-Kaz: people 69, each 54, parents 27, 11 doctor 11, wizard, mom, dad, strong, husband 10, angry, uncle 8.

- Water-Rus: Cold 48, net 42, to drink 20, Sea 18, transparent 15, spring 14, liquid, river 11, wet, drinking 9, live, land 8;

- Water-Kaz: Sea 38, River13, valve 12, lake, transparent 11, clean, cold 10, life 8.

The words were the same, but the images they conjured were different. The underlying meanings were also different. Certainly, collective stereotypes and systems of values both are present in the first and second case, but the implication is different. Despite a certain logicality of the Kazakhstan "version" of the speech, the word doesn't express the full attribute of the state of affairs in the speech. The "ideal" event isn't present. Perhaps, in relation to the association recorded in Kazakhstan, it is possible to talk about a lack of ethnic stereotypes. In the Kazakh version, firstly, "the thinking of crowds" - the stereotypical and repetitive images are fixed. Any language as a certain spiritual substance always changes and has no property to remain the same from point to point. First of all, in language practice of the Kazakhstan PostSoviet discourse, processes of impoverishment and standardization of Russian are obvious. But any contents, including language, has to change, otherwise they "will simply slip" out of consciousness. In the modern version of "the 
Kazakhstan word" again, as well as in the recent and forgotten Soviet years, only speech patterns when everything is right are found, there is nothing uncertain, indistinct, or kept back.

In this "version" of the language only mass performances, stereotyped and repetitive images are obvious. The first and most obvious: a craving for conventional stereotypes, standard and tarnish language.

For this reason, in language of the majority of official Russian-speaking and Kazakh mass media of Kazakhstan's exclusively bookish lexicon, which is distinguished from the Soviet period prevails. A researcher of mass media emphasizes:

It is possible to assume that media are not only neutral transmission media of information, the ability to transformation, the reformatory, expressional and symbolical opportunities, the specific forms of manifestation participate in process of identification of meaning.

Moreover, modern mass media, in particular, intensively appeals to the emotional, affective side of a person, participating, thus, in reorganization of structure of perception and knowledge (Günter Hans 2006: 5).

In the Kazakhstan publicity discourse, the second "coming" of an office language is available. This is negative as it stultifies consciousness. An office language is present on republican on TV in government messages, as well as in local advertisements. In all this there is no "ideal" event, and there are only mass images. That is also apparent in most cases of modern Kazakhstan journalism, such as television discourse or a judicial debate. The latest small patterns of the language addressed from the state to the people are thus: "a youth personnel reserve", "a culture factor during a crisis era", "breakthrough projects", "programs on development of potential of youth" and so forth.

In addition to elementary literacy, extensive fragments of official discourse reminiscent of Soviets watches: the repetition of the same, but in different words, the absence of many of the concepts of corporeal reality. Once again, the familiar Soviet simulative and its new incarnation of Kazakhstan, in which means are as far from reality's the former Soviet-internationalist. Against in the30s of the twentieth century in favor "hollow words" - verbal Hand wavingoptimization, formatting. From the same number of creation of new slogan "One hundred schools- one hundred hospitals", "Salamatty Kazakhstan", "Employment Roadmap-2020", "Business Road Map 2020", "Kazakhstan Information." Nowadays organizations have appeared with names like NPP, SSIF, ENPF, and SEC that are looking for easy ways of a profit as agents, nothing else.

In all other cases we found only tarnished and standard language, accompanied by the drafters of ignorance of a text. From the press release of the party "Adilet": "In his speech Sydyhov T.S. noted that in the light of wellknown recent labor disputes there is an urgent need for a close cooperation of the leader of the trade union and the employer". 
The inevitable question-what is meant by "in the light of labor conflicts"? What is meant by "dense (close) interaction of a leader and an employer"? Most likely, it will remain without distinct answer. That the anonymous founder of the press release of Adilet party of November 7, 2012 tries to inform readers: "One of the main institutes urged to protect interests of a worker is the labor union, however trade-union construction is in RK without signs of the transformations conforming to modern requirements".

The problem is that these bulky verbal clichés do not cost anything, and they do not evoke anything in the minds of those to whom they are addressed. As a rule, the minimization of concepts in the Kazakh official discourse is complemented by endless repetition and appeal to the sense of listeners and viewers. Cognitive structures remain in consciousness if they are transformed. We will refer to a phenomenon of a semantic satiation: repetition of the same word or group of words can lead to lose the sense of these words. Really, any conscious contents have to be changed continuously, otherwise it "will escape" from consciousness. There is a phenomenon of cognition, received in abnormal psychology, called "logic-chopping". Logic-chopping in many and in this example also serves as a main feature of Kazakhstan's discourse. The description of this phenomenon includes: weakness of judgment, circumlocution, and pretentious-estimated position gravitas. All this in real communication is combined with an attempt to make communication unambiguous and widely understood.

A number of the examples confirming reasoning as the distinguishing line of the Kazakhstan discourse can be given in scientific and art style. So, the book devoted to languages of people of Kazakhstan consists of such unconvincing sets of offers: "On a sovereignty platform in the last decades of the last century at the forefront there was a question of functioning of language";

In the state which again gained independence such socially significant undertaking as the language movement in the context of restoration of justice of languages in the rights of functioning for the purpose of achievement of multilateral language development of Kazakhstan which includes development of a state language as one of the languages which are most restrained in the rights of functioning and languages of other nationalities and on their base of bilingualism, multilingualism involving the state language (Khasanov 2005: 213).

Those are also examples of verbal designs from "The standard training program" for journalists (Almaty 2007) the course of "Bases of Publicity Creativity": "This subject develops a communicative role in the journalist and teaches to forms of dialogue, polemic, ideas of journalism, estimated thinking, selection of the facts"; "Skill is the correct technique of mastering terms, and also training of presenting of reality" (it is quoted literally).

Of course, these examples can be attributed only to the speech errors of their authors. But the vast majority of scientific and journalistic texts within 
evitable regularity will differ by logic-chopping, by officials (office language), and simulation of anthropocentric interpretation.

However, and in the Kazakhstan art story (Esenaman 2010) claiming a certain post in modern Kazakhstan literature, the same mix of a officials with colloquial lexicon:

\footnotetext{
"The drugs subject for me was familiar";

"I tried to make a suicide, but I have been rescued";

"I am not gifted to write (meaning: I don't have any talent to be a writer), for example, something, and you, having this gift, simply you thrust it into your ass";

"Besides, I had to respect, and attend a course on yoga exercises system";

"The army's good. There you will stop feeling depressed. You will not have time".
}

May we speak about any rhetorical space of words from this story or other modern literary opus? After all, it is also an experience of the development of the world, let it be individual and expressed in art consciousness. Anyway, it isn't necessary to argue on the birth of special language of the youth. No doubts, that is a discursive choice by the author of the literary text. So, according to the author, the Kazakhstan teenagers express their thoughts that way. But, a certain erudition of the author and a little far-fetched teenage break, "Hardcore", as well as many Kazakhstan literary texts of the last years, are remembered by a combination of a strange but very typical and indicative of the "adult" speech combined with youth catch phrases. They are, incidentally, quite unpretentious and do not cause absurd speech as it might be desired by modern prose. Our assumption does not matter, since modern teenagers do not speak that way. Russian language writers and bloggers are a bizarre recombination of conversational patterns with a bookish pathos. On a journalistic level, this is stated by Herold Belger,

And I sometimes think, all on top of each other are too similar. Everywhere is the same traditional Kazakh style. While reading there is little left in your memory. I remember when I was taught in the Kazakh school and there we wrote pretentious (pathos) poems. Here now it is the same (Belger 2014: 5).

In literary discourse, Kazakhstan literature is philosophically naive, a primitive graphomania, including poor literary style. This is the language of our post-Soviet space, with a medial, lean, and cosmopolite surface.

There is a variable connection of colloquial patterns. It is bookish and demonstrates pathos once again, and these patterns remind us the last 50-60 years of the last century. Nature of "movement" from a subject to a general word in both chronological periods from the rational point of view was broken: there were no adequate communication between specific names and the generalizing concepts. At such prevailing "verbalism" thinking intrinsic characteristics were left aside, as a result, reducing speech efficiency. S. Moskovichi interprets: 
There are two and only two types of thinking intend to explain the reality: the first focuses on the idea, the concept, and the second - the idea of image. The first act is according to the laws of reason and evidence, the second appeals to the laws of memory and suggestion (Moscovichi 1998: 139).

In the speech of rationally conceiving native speaker the following hierarchy is built: idea concept + idea image; in the given Kazakhstan examples, the idea concept merges the idea images. As a result it brings:

1) the change of form of a categorization: from social and rated, to a categorization to non-standard (from conceptual structures to sensual images);

2) the change of emotional coloring of the internal experience reflected in consciousness;

3) the change of personal sense.

Kazakh words conjure up images, obviously already in the minds of readers, listeners and consumers. At the same time, they relieve those who use them from the obligation to think. Let us note, that in Kazakhstan real speech practice the patterns of hippie slang have not been fixed, instead, we can observe criminal jargon both in adult and youth language. In the Russianspeaking Kazakh discourse there is a fixed central feature of the post-Soviet discourse -it has "reduced" and "plastic" (artificial) features. The quality of the language can be calculated in written language and uttered by someone in spoken language.

Author of the book The Russian language on the verge of a nervous breakdown M. Krongauz analyses the realities of Russia, saying: "After the perestroika we have experienced at least three verbal war: gangster, professional and glamorous...three periods, three modes" (Krongauz 2008: 132). But now, many of the censured "fashion" items are somewhat enriched in the Russian language in Russia. They safely passed Kazakhstan, although elements of computer vocabulary and glamorous "twitter" can still be found.

Perhaps it is for this slang is more popular between the Kazakh youth. The word "competent" (explanatory) is an incomplete replacement of the Russian equivalent of the "correct" or "right". Indicative in Russian speech culture word leaders in recent years use "right", "pathetic", "jesture" (every word-protest attitudes). In Kazakhstan nowadays, youth discourse has not set similar standards and stereotypes of social behavior. Recent Kazakh speech samples show the provincial grumbling about everything around. The most common clichés are: "civilno" meaning civilized (everything is good, but not at home), "bespontovy" meaning (simple or stupid), "nechto" meaning something (as the highest grade of something) - popular in the 90s, the words in the Russian youth. "And anyway, there (in London, Paris, Bloomington) all is so civilized".

The most important aspect isn't found in a youth sociolect of Kazakhstan - the thought-over following of a certain ideology. Eventually, the Kazakhstan youth discourse won't be a phenomenon of post-modern culture (as it is recorded in all other countries), it is mostly painfully quiet and deeply 
provincial, formed through ethnic and culturological stereotypes. The growing (or matureding) Kazakhstan conditions are rather "correct" following to "adult" samples, out of any alternatives. The Kazakhstan sociologists note: "At the same time interview with respondents allows to conclude about lack of rigid opposing (open or hidden) the Kazakhstan youth with world of adults, with its social rules and norms" (Molotov Cocktail 2014: 137).

Words have already become fictional, but not as an event in any way. Perhaps, therefore, in recent years in the Kazakhstan mass culture, as well as in Russian culture for the last five years, the rhetorical principles and receptions of a manipulation by mass audience (advertising texts, the propaganda companies, etc.) with the suggestive principles of speech therapy can be observed. Firstly, simplification of sense concerns that. Really, consumer mass or the mass electing of someone is relieved of excess efforts. In relation to public speech behavior in Kazakhstan, there is a simplification of sense. In lexicon of the accuser-antiglobalist, it can be designated as "a fooling of blockheads". Commonality of an image is commonality of creation of thought and the speech. Thus, everything is correct and nothing is indistinct. Commonality of an image is commonality of creation of thought and the speech. Thus everything is correct and nothing is vague.

Perhaps, in principle, the so-called "inconsistent language structures" are impossible in our case. Like the following: "The Unbearable Lightness of Being" (the name of the movie), "I will revenge Ukraine with (or by) love" (S. Paradzhanov's phrase). Game with vague sense at simplification of sense is simply inconceivable and isn't allowed consciously.

Any public shift shakes (shocks) language but what has "changed" in the Kazakhstan rhetorical manifestation including in its youth performance?

The definitive answer to this question is still difficult. Therefore, the demagogy itself substitutes a real art of conducting dispute. Actually, examples of speech thinking of the Kazakhstan are not numerous debaters (officials, deputies, political scientists) on the Kazakhstan TV screen clearly demonstrate the phenomenon of "east reasoning (in a negative way)" again: weakness of judgments, loquacity, a pretentious and estimated position, tendency in big generalizations concerning insignificant objects of judgment, inappropriate pathos. In any culture, typical reaction to absurdity is always laughable. It both were, and is, present at due surplus in youth speech culture, and presently in the Russian youth discourse it is most obviously expressed in language parodying in "the Albanian language" or "language of net guys (bastards)", that it is possible to refer to protest culture. KVN (klub veserlyh i nahodchivyh -initial letters of these words KVN which means the club of joyful and smart guys, we have such TV programs across former Soviet space) guys imposed their understanding of life and the speech in recent 90 s of the last century which in a big way degenerated in pop culture. In Russia it has commercially taken place "Comedy club" and "Nasha Russia", in Kazakhstan _ "Kyzkylyga" and 
"our KZAShA". A priori would be too simple to attribute all this to manifestations of the coming petty-bourgeois culture. Modern speech KVN tricks are, as a rule, at the same time, criminal and expressive. This fragment of a youth sociolect (social speech patterns) for the most part, is only hidden or obvious aggression (political, ethnic, and sexual).

What is still typical to Kazakh stand is course: the familiar voice of the Soviet practice of vandalism or rhetorical balance?

Kazakhstan's post-Soviet discourse in our eyes is composed of three unequal constituents: the Western model of rhetoric, Eastern (Muslim) orator/and the Soviet manner of speech. A bizarre link, but it is viable. Speech etiquette and verbal behavior of certain people allows you to see more than just the language of the addiction era. It is natural that ethno-psychologists distinguish high contextual cultures (with the predominating principle [what to say]) and low-contextual (as they say with whom, in what situation there is a communication).

It is also obvious that in the swatches of speeches, the social consciousness of its epoch is reflected. For a Kazakh speaker, the western manner of speaking is a kind of "cover". Kazakh everyday manifestations of Islamic culture can hardly be attributed to the influence of real speech. Especially when clerics (religion) are often closer to the style of the Soviet era: it's unaddressed treatment, abstract reasoning and external correctness. More interesting stylistic aspirations are within the Turkish youth, such as the address formula, respectful tone and lack of foul language.

Where will this lead? To what it will lead? So far, this isn't known. However, the desire to see only one world, perhaps, limits and simplifies vital values. Language of mass communication is momentary and fleeting, nevertheless, this creates the world which seems reality to "public". In television and media "texts" (including Internet media), it is difficult to find desire of the Kazakhstan expert communicators to see the listeners (and interlocutors) as equivalent partners in communication, the living and acting subjects. For them, we are more "vessels" which need to be filled with the content.

At a subjective view of the author, "mass idols" in Kazakhstan are absent. Those who apply for it, show all three types of rhetoric in their texture (collision). They are more filling themselves from the West, with undoubted Soviet roots and in some cases - microscopic doses of Islamic spirit.

One of possible, but not the last, explanations of specifics of the Kazakhstan Russian-speaking discourse are a weak quality of a presentation of Russian in the Kazakhstan textbooks and programs. However, these occur at the same time and are a consequence of the current situation. Most likely, the statement "borders of my language are borders of my world" fits in all cases when the person speaks.

Yuri Murashov defines the essence of the socialist communication: 
Society with poor institutionalization of social and mental internalization of writing under the influence of new electro-acoustic communication capabilities so-called "secondary orality" inclined to abandon a differentiated analysis of semantic relations based on written specifications abstraction, formalization and self-reflection, in favor of direct communication that is driven by immediacy and totality in understanding the meaning (Murashov 2013:167).

In everyday discourse, this is recently reflected in the reproduction of an aggressive Soviet communications. There are still frequent forgotten clichés and curses: "Take a taxi, if you do not like a bus"; "You can retire, there are people waiting for your position." In turn sporadically "go forth" jokes -it's only a paraphrase Russian counterparts. All jokes about (Kazakh) President-tracing paper with exactly the same jokes about Putin.

Separation of the Kazakhstan society into two information spaces (Kazakh-speaking and Russian-speaking) in this case, has no value. Certainly, in each of these spaces there are leaders of opinion and the list of the most important and most discussed questions.

The Soviet identity is more peculiar to Kazakh-speaking medial space. Kazakh discourse has insignificant differences from the Russian medial space. The same culturological concepts connected with language and extreme glorification of the past, but only with local color. Yury Murashov defines an essence of socialist communication:

Societies with an undeveloped social institutionalization and mental internalization of the writing (text) under the influence of new electro-acoustic communicative opportunities so-called "a secondary oral speech" are inclined to refuse the differentiated analysis of the semantic links based on written characteristics of abstraction, formalization and a self-reflection in favor of the direct communication which is guided by a spontaneity and totality in understanding of sense (Murashov 2013: 167).

In a domestic discourse, the last was reflected in reproduction of aggressive Soviet communication. The forgotten clichés and curses returned and became frequent: "Go by a taxi if the bus isn't pleasant"; "You can leave (meaning: at workplace), there are people on your position". In time, "walking" (meaning: popular) jokes are exclusively being retold of the Russian analogies (equivalents). All jokes about the president (of Kazakhstan) are comparable to jokes about Putin.

The language is associated with the comprehension of reality. Dialogue on an initial condition is also not enough for the Kazakhstan speech samples. I will notice that dialogue baseline (type of speech) can be present even at one phrase thrown at a meeting: "Women, don't give birth to communists". 


\section{BIBLIOGRAFY}

BOURDIEU, P. (1995), "Structure of habitus, practice", in Contemporary Social Theory, Novosibirsk, Publishing House of the Novosibirsk University, 16-39.

ESENAMAN, Z. (2010), Hardcore, Almaty.

GEROLD BELGER INTERVIEW (2014), Newspaper Sayasi-Kalam. Tribune, № 13, October 29, 4.

GizDATOV, G.G. (1998), Cognitive models in speech activity, Almaty, Gylym.

GuNTHER, H. (2006), "Introduction", in Soviet government and media. Collection of articles edited by Hans Gunther and Sabina Haensgen, St. Petersburg, Academic Project, 516.

HASANOV, B. (2005), Languages of Kazakhstan, Almaty.

KJeLL, L.; ZIEGLER, D. (1997), Theories of Personality (basic provisions, research and application), St. Petersburg, Peter Press.

KRONGAUZ, M. (2008), Russian language on the verge of a nervous breakdown, Moscow, Languages of Slavic culture.

MOLOTOV COCKTAIL (2014), Molotov cocktail. Anatomy of Kazakh youth, Almaty, Alliance think tank.

Moscovici, S. (1998), Century crowds. Historical treatise on the psychology of the masses, Moscow, Center for Psychology and Psychotherapy.

Murashov, Y. (2013), "East. Radio", in Jambul Dzhabaev: Adventures bard in the Soviet Union, Moscow, New Literary Review, 138-170.

RUSSIAN DICTIONARY ASSOCIATIVE (1994), Direct dictionary: from stimulus to response, Book 1, Moscow, "Pomovsky and Partners".

ZASLAVSKY, T.I. (2004), Modern Russian society: social transformation mechanism, Moscow, Business. 